\title{
Methodological measurement basis environmental safety in construction and operation of water management facilities
}

\author{
V. L. Bondarenko, ${ }^{1, *}$, E.D. Hecuriani ${ }^{2}$, O. V. Klimenko ${ }^{3}$ and E. A. Semenova ${ }^{4}$ \\ ${ }^{1}$ Novocherkassk Engineering and Land Reclamation Institute of the Don State \\ University of Agriculture, Novocherkassk, Russia \\ ${ }^{2}$ M.I. Platov South-Russian State Technical University (Novocherkassk Polytechnic \\ Institute), 132, Prosvescheniya str., Novocherkassk, 346428, Russia \\ ${ }^{3}$ Director of the branch WTL (USA) in Asia, 7A, build. 2, Novatorov str., Moscow, \\ 119421, Russia \\ ${ }^{4}$ North-Caucasus Federal University (Branch in Pyatigorsk), 56, 40-let Oktyabrya, \\ Pyatigorsk, 357500, Russia
}

\begin{abstract}
Based on the results of monitoring studies of existing and under construction water management facilities within the basin geosystems of the Kuban, Lower Don and Terek river, using a systematic approach of developing methodological framework for assessing environmental safety in space and time on the model of the system "OP-SES-PM", in which the vector properties are determined by the structure of this system. Taking the water management facility as a source of environmental safety, the concept of environmental safety is defined. Which is interconnected with the ecological state of the water management facility, considered as an "object of activity, as part of the environmental-technical system" "Natural environment-Object of activity-Population". Based on the analysis of the processes of interaction between the components of the system "OP-SESPM" conceptual statements of environmental safety have been formulated
\end{abstract}

\section{Introduction}

The modern development of the "Society" within the global system of "Nature-SocietyMan" and, accordingly, at the hierarchical levels of local basin geosystems, in areas of which water resources are formed in the form of surface and underground run-off, and almost all types of economic activity (EA) are carried out which are inherently interrelated with the use of water resources.

The use of water resources in EA in practice is done through the construction of water facilities, which include a set of various types of hydraulic structures (HS) in the form of reservoirs of waterworks, water supply, water transporting and other types of HS that provide in-basin regulation or redistribution of water flow to ensure sustainable calculation of estimated usage $(\mathrm{Qm} 3 / \mathrm{s})$ of natural water of various consumers in industrial,

\footnotetext{
*Corresponding author: serdariaziev@gmail.com
} 
agricultural production, domestic infrastructure and water users, such as hydroelectric power stations, nuclear power plants, thermal power plants, etc.

The use of water resources in EA is a special type of activity and is integral and interlinked with the problem of water on a global scale, which is determined by the processes of global water cycle within the Earth's biosphere (We.b. $=1 \times 1010 \mathrm{~km} 3)$ as the basis for all vital processes of living matter in which water is the main and dominant natural resource.

The formation processes of quantitative and qualitative indicators of water resources within borders of basin geosystems (BBG) and the targeted use in various technological processes of EA determines objective and subjective transformations in natural environments (NE) - surface layers of the atmosphere (up to $10 \mathrm{~km} \mathrm{high);} \mathrm{the} \mathrm{earth's}$ surface at the boundary of the watershed line of the catchment area of the hydrographic river network; the upper layers of the lithosphere (up to $300 \mathrm{~m}$ deep), where underground water flow is formed; soil with underlying mineralization. Transformations in natural environments under the influence of the considered type of EA cause certain changes in the natural properties and intensity of movement of the flows of matter, energy, information (MEI), which determine the ecological state (ES), as the dominant factor of environmental safety (ES) in the BBG under consideration. [1-5]

\section{Materials and Methods}

Based on the analysis on the results of the study of domestic [5-12] and foreign [11-25] sources, a conclusion can be made that the the concept of ES is quite widespread and covers almost all types of EA, and therefore, for each type of EA, specific justification is required, in which the concept will reflect all necessary quantitative and qualitative aspects of changes in NE under the influence of a technogenic component [5-7].

For the type of EA such as the use of water resources, ES in the construction and operation of water facilities as objects of activity ("OA") being a part of environmentaltechnical systems (NTS) "Natural environment-Object of activity-Population" ("NE-OA-P "), is regarded as a defining basic term, acquires a practical real understanding in the system: "Object of protection-Source of environmental safety-Protective measures" ("OPSES-PM"), Where as "OP" can be "NE" and living "P "in the zones of influence of "OA" [5-9].

In general terms, the system "OP-SES-PM" can include all "OP", "SES" and the necessary set of "PM". Due to researchers has been established that the studying of the processes of interaction of all components in this system under the continuous exchange of MEI streams in space and time causes certain difficulties. Therefore, when assessing the level of ES, it is advisable to distinguish specific "OP" from the whole set, which is affected by a specific "SES" in combination with "PM". System's model with the selected "OP" is presented in Figure 1.

In this system (Fig. 1), vector notation is used: En(t) - input matter-energy streams at that affect the system; $\mathrm{S}(\mathrm{t})$ is the state of the system determined by the processes between the components of the "OP-SES-PM" system and the surrounding NE Ene(t). Vector properties are determined by the structure of the system. 


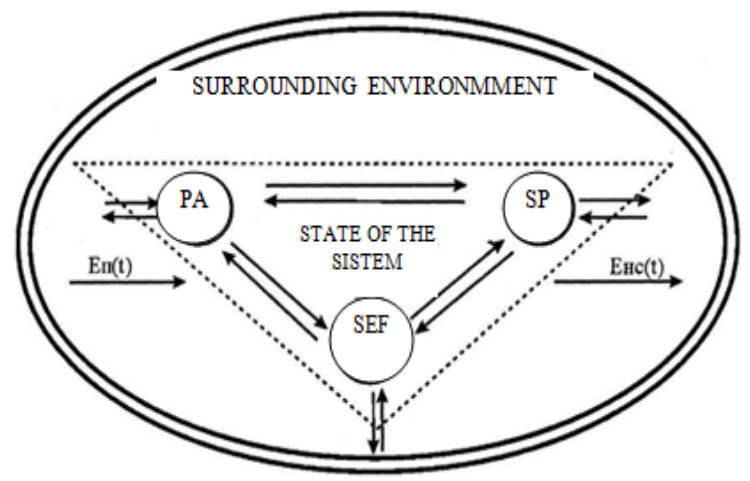

Fig. 1. Model of interaction between components of the «OP-SES-PM» system

\section{Results and Discussions}

In justifying the fundamental categories of "ES" in the considered form of EA, where water management facilities are regarded as "SES", based on the research results, it is recommended to proceed from the interpretation of "SES" as a possible cause of damage to the living "P" and "NE" in the areas of influence of "OA", that acts as a part of the ETS "OP-SES-PM" [5-12]. Environmental hazard ("EH") emanating from "SES" is one of the fundamental concepts, which is inherently interconnected by a number of additional concepts, such as risk; crash accident; disaster.

As part of the operating and developed ETS "NE-OA-P", "OA" as the source of "SES", is the main one by its operation forms ecological state in areas of the impact of BBG, which determines the quantitative and qualitative criterias of "ES" [1-12]. Based on the results of several years of research of existing and developed "OA" within the basin geosystems of the Kuban, Lower Don, Terek river, it was established that the ES formed by ecological state in the space and time of the zones of influence of "OA", determined by the changes introduced during the construction and operation of the natural processes between the components (biotic and abiotic) of "NE" and the vital activity of "P" as part of the ETS "NE-OA-P".

The introduced changes in "NE" and the vital functions of "P" during the construction and operation of "OA" are determined by the complex system ecological monitoring (CSEM) [1-7] based on the results of which quantitative and qualitative criterias of ES are defined, describing the trend direction in the ongoing transformations in "NE" and the vital activity of "P" under the influence of "OA".

On the system scale, "ES" in space and time is considered as ecological state in the zones of influence of "OA" under the influence of the created additional MEI streams, the intensity of which depends on the processes of transformations in "NE" and vital activity of "P". Based on an analysis of the interactions between "OA", "NE" and the local "P" as part of the ETS "NE-OA-P" ES can be represented in a number of statements: -ES in the areas of influence of "OA" is interconnected with the local "P" and "NE"; ES in areas of influence is inherent interconnected with energy consumption, which determines the generation, storage and conversion of various forms of energy; ES "OA" shows as a result of the uncontrolled release of streams of energy and matter accumulated in "OA". Violation of "ES" in the areas of influence of "OA" is a consequence of the chain of prerequisites determined at the stages of design, construction and operation, as a result of which the energy of the matter is released from "OA"; the beginning of the cause-and-effect chain of 
violation of "ES" in the system of "OP-SES-PM" is "OA" which does not meet modern requirements of environmental safety.

\section{Summary}

Based on the research results of methodological framework for assessing of ES of water management facilities during the periods of their construction and operation, it was established, that ES 'OA' is formed by ecological state in the areas of influence of "OA", which is formed in the cause-and-effect chain ot the stages of design, construction and subsequent operation.

Quantitative and qualitative criterias of ES are determined on the basis of the results of CSEM in the areas of influence of "OA".

It is recommended to evaluate the level of ES "OA" in the system of "OP-SES-PM"

\section{References}

1. A.L. Bolsherotov, System for assessment of environmental safety of construction, Publisher of Construction university association, Moscow. ISBN 978-5-93093-757 (2010)

2 E.E. Rumyanceva, U.D. Gubernsky, T.U. Kulakova, Environmental safety of construction materials, designs and products (MoscowUniversity, book) (ISBN 598699-010-2)

3. T.A. Horuzhaya, Assessment of environmental safety, («Service book», Moscow, 2002)

4. A.G. Shmal, Methodics of creation of national system on environmental safety, Environmental harbinger of Russia, 7, 57-59 (2005)

5. A.G. Shmal, Methodological basis for creating environmental safety system (MP «IKC» BNTV, Bronnici, 2000)

6. V.L. Bondarenko, A.B. Ilyasov, E.D. Hecuriani, Methodological basis of environmental-technical system in operation of water management facilities: areas of basins, monography (Novocherkassk, URGPU (NPI), 2019)

7. V.L. Bondarenko, E.A. Semenova, A.V. Alipherov, O.V. Klimenko, Environmentaltechnical systems in operation of water management facilities: areas of basin geosystems, monography (Novocherkassk, URGPU (NPI), 2016)

8. V.A. Volosuchin, V.L. Bondarenko, Basics of methodological systematic analysis environmental-technical systems of operation of water management facilities, bulletin «Usage and protection of natural resources in Russia», 5, 15-24, (2015)

9. P. Saling, A. Kicherer, B. Dittrich-Kramer, R. Wittlinger, W. Zombik, I. Schmidt, W. Schrott and S. Schmidt, Life Cycle Management,Eco-efficiency Analysis by BASF, The Method (Germany, BASF, 2002)

10. P. Saling, R. Hofer (ed), "Metrics for Sustainability” as part of RSC Green Chemistry Sustainable Solutions for Modern Economies Edited by Rainer Hufer; The Royal Society of Chemistry; „Green Chemistry Series“ edited by the Royal Society of Chemistry Series Editors: J. Clark, University of York; G. Kraus, Iowa State University, 4, 25-37 (2009)

11. River Basins Under. Ed. Chernyaeva A., (Yekaterinburg, Moscow., RosNIIIVH "Agroecology",1999)

12. Ged R. Davis, Energy for Planet Earth, In the World of Science, 11, 7-16 (1990) 
13. E.D. Khetsuriani, L.N. Fesenko, V.P. Kostyukov, T.E. Khetsuriani, Obtaining a regression equation and evaluating their adequacy for analyzing field studies, Obtaining a regression equation and evaluating their adequacy for analyzing field data Research, Norwegian Journal of the Development of International Science, 9 (2), 69-72 (2017)

14. D. Barnes, F. Galgani, R. Thompson and M. Barlaz, The accumulation and fragmentation of plastic waste in global conditions, Phil. Transaction R. Soc. B, 364, 1985-1998 (2009)

14. M.J. Behrenfeld and E. Boss, Beam attenuation and chlorophyll concentration as alternative optical indicators of phytoplankton biomass, J. Mar. Res, 64, 431-451 (2006)

15. M. J. I. Berenfeld, P.G. Falkowski, The rate of photosynthesis obtained from satellite concentration of chlorophyll Limnol, Oceanogr, 42, 1-20 (1997)

16. M. Cole et al., Microplastic ingestion, Zooplankton Environment, Sci. Technol, 47, 6646-6655 (2001),

17. M. Dellnitz, G. Froyland, C. Horenkamp, K. Padberg-Gehle and A. SenGupta, Seasonal variability of subpolar cycles in the Southern Ocean: a numerical study based on transport operators Non-linear process, Geophys, 16, 655-664 (2009)

18. G. Froyland, K. Padberg, M.H. England and A-M Treguier, Detection of Coherent Oceanic Structures Using Phys Operators, Rev. Lett, 98, 224503.(2007)

19. M.R. Gregory, Environmental Impacts of Plastic Garbage in Marine Conditions Entangling, Swallowing, Strangulation, Suspension, Hitchhiking and Alien Intrusion Phil, Trans. R. Soc, B 364, 2013-2025 (2009)

20. L. C-M. Lebreton, S.D. Greer and J.C. Borrero, Numerical simulation of floating debris in the oceans, March. Pollut. Bull, 64, 653-661 (2012)

21. R.C. Thompson, C.J. Moore, vom Saal F.S. and S.H. Swan, Plastics, the environment and human health: current consensus and future trends Phil, Trans. R. Soc. B, 364, 2153-2166 (2009)

22. E. VanSebille, Adrift.org.au, a free, fast, and easy tool for the quantitative study of planktonic drift in the global ocean J. Exp. Mar. Biol, Ecology, 461, 317-22 (2014)

23. T.L. Delworth etal., GFDL CM2 Models with Global Climate Connectivity: I. Formulation and Simulation Characteristics, J. Clim., 19, 643-674 (2006)

24. Z. Babiński, Modern Processes of the Lower Cretan Vistula (geographical work), Wroclaw-Warsaw-Krakow, v. 157, 172 (1992)

25. G.P. Williams, M.G. Wolman, Influence of dams downstream on alluvial rivers, professional article by the US Geological Survey, 1286, 83 (1984)

26. G.G. Onishchenko, Influence of the state of the environment on public health. Unresolved problems, Gig. Isan, 1, 3-1 .(2003)

27. D.J. Dawson, D.P. Sartory, Microbiological safety of water, Brit. Med. Bull, 56(1), 74 $-83(2000)$

28. P. Puyment, A. Berte, M. Prevost, B. Menard, B. Barbeau, Occurence of pathogenic microorganisms in the Suit-Lawrence River (Canada) and comparison of health risks for population of using it as their sourse of drinking water, Can. J. Microbiol, 46(6), $565-576(2000)$ 